\title{
Hitting the Pause Button: The Impact of COVID-19 on Cervical Cancer Prevention, Screening and Treatment Access in Indonesia
}

\author{
Belinda Rina Marie Spagnoletti ${ }^{1,2}$, Hanum Atikasari ${ }^{1}$, Linda Rae Bennett ${ }^{1}$, Henny \\ M.A.R. Putri ${ }^{3}$, Miranda Rachellina ${ }^{4}$, Ardhina Ramania ${ }^{2}$
}

\begin{abstract}
${ }^{1}$ Nossal Institute for Global Health, Melbourne School for Population and Global Health, University of Melbourne, Melbourne, Australia. ${ }^{2}$ Center for Reproductive Health, Faculty of Medicine, Public Health and Nursing, Gadjah Mada University, Yogyakarta, Indonesia. ${ }^{3}$ Gatot Soebroto Army Hospital (RSPAD Gatot Soebroto), Jakarta, Indonesia. ${ }^{4}$ Indonesian Cancer Foundation - Jakarta Branch (YKI-DKI), Jakarta, Indonesia.
\end{abstract}

\begin{abstract}
As Indonesia grapples with COVID-19, it remains vital that other crucial health interventions continue to be prioritised to minimise the overall health footprint of the epidemic. Cervical cancer is a preventable disease, yet it is the most lethal female cancer in Indonesia, responsible for more than 18,000 deaths each year. Thanks to the efforts of several key groups driving health reforms to step up cervical cancer control in recent years, Indonesia has a national screening program and, up until late 2019, a HPV vaccination pilot program was being rolled out across five provinces. An interdisciplinary four-year study exploring the experiences of and health system responses to cervical cancer in Indonesia was underway when the COVID-19 pandemic emerged. Alarmingly, the widespread restrictions on citizens' mobility and the redistribution of resources to the COVID-19 response has resulted in key services for cervical cancer prevention and screening being paused indefinitely, without a clear path forward. Treatment seeking, and the availability of support services for women with a cervical cancer diagnosis have also been interrupted. If unaddressed, these pauses will lead to an increase in women presenting with late stage cervical cancer, for which treatment is more invasive and costly, with a lower chance of survival. We are also concerned for the future generation of women in Indonesia, who, without access to affordable HPV vaccination, will face a heightened risk of developing cervical cancer compared with their peers from countries that have prioritised investing in this life saving vaccine.
\end{abstract}

Keywords: Cervical cancer- health care access- pandemic- early detection

\section{Introduction}

The impact of the COVID-19 pandemic must be considered not only in terms of the lives lost by those who have contracted the virus, but also in terms of the total lives lost as a result of government responses to the pandemic, and the economic and social effects of the pandemic on health. This combined impact is now being conceptualised as the overall health footprint of the pandemic [1]. Managing the pandemic's impact on chronic and non-communicable diseases is critical to reducing the health footprint of COVID-19. Cervical cancer remains of paramount concern in Indonesia, with an average of 50 women dying from the disease each day prior to the COVID-19 pandemic, making it the most lethal female reproductive cancer in the country [2]. Yet cervical cancer is preventable through human papillomavirus (HPV) vaccination and highly treatable if diagnosed at its earliest stages.

Cervical cancer screening is a crucial intervention because this form of cancer tends to be asymptomatic in its early stages. Like the majority of its Asian neighbours 
(excepting Malaysia and Bhutan), HPV vaccination is not yet included in Indonesia's national immunisation schedule. The average cost of vaccination is approximately IDR 1 million (USD 68) per dose, making it out of reach for most Indonesians. Indonesia theoretically has a national cervical cancer screening program targeting married women aged 30 to 50. However, between 2014 and 2018 less than $8 \%$ of the target population had actually been screened [3].

A collaborative four-year study of women's experiences of cervical cancer, and Indonesia's response to cervical cancer control, was underway when COVID-19 struck. This research is being conducted by an international team of co-researchers from the Center for Reproductive Health at Universitas Gadjah Mada and the Nossal Institute for Global Health at the University of Melbourne. Despite the initiation of social distancing and lockdown measures, the research team have continued interviewing health sector informants via Zoom and WhatsApp. Since March 2020 we have interviewed 27 informants working in clinics, community-based organisations and hospitals across the Indonesian capital, Jakarta. Here we describe some of the reported impacts of the COVID-19 pandemic on cervical cancer prevention, early detection, treatment and care occurring in the nation's capital, shared by our research informants.

\section{Adjustments to service delivery}

Indonesia's densely populated capital city, Jakarta, was the initial epicentre of the country's COVID-19 outbreak, and on 20 March 2020, Governor Anies Baswedan declared a state of emergency. Several weeks later, on April 13, 2020, President Joko Widodo handed down a decree declaring the country's COVID-19 epidemic to be a National Disaster.

Ahead of these official announcements, from midMarch the Indonesian Cancer Foundation's (ICF) Jakarta branch closed its clinic, and remained shut for three months due to social distancing and the work-at-home-ifyou-can directives. This meant both HPV vaccination and cervical cancer screening services were unavailable within the locales of the ICF clinic services. Upon reopening in June 2020, clinic hours have been drastically reduced, down from five to two days per week. Additionally, outreach screening has been suspended indefinitely. As the primary method for screening large numbers of women is via mass outreach screening events, social distancing will be a key consideration in the scheduling of future events and the ongoing risk of COVID-19 transmission will likely result in fewer women taking part.

A private HPV vaccination clinic involved in our study which has multiple branches across Central Jakarta managed a rapid shift to mobile health service delivery and has maintained a stable patient flow during the current pandemic. However, the client base of this clinic is upper-middle class and elite women, due to the relatively high cost of services.

Halfway houses that offer modest accommodation to cancer patients undergoing treatment who live outside of Jakarta have had to refuse access to any new patients due to lockdown requirements and travel bans. Only those women who were undergoing treatment when COVID-19 hit have been permitted to stay. This has hindered women from other provinces, who do not have relatives living in Jakarta or the ability to selffund alternative accommodation, from receiving timely treatment.

In Jakarta's cancer referral hospitals, outpatient services and chemotherapy and radiotherapy have been largely uninterrupted. However, reductions occured in surgical capacity in relation to radical hysterectomy, the recommended treatment for women with early stage cervical cancer, during March and April when this procedure was unavailable. Surgical treatment for cervical cancer in Jakarta hospitals resumed in June, and has resulted in longer than normal waiting times due to the backlog caused by the two month pause. We note that, in the case of a progressive disease such as cervical cancer, a two-month delay in accessing treatment may well result in a significant advance in the disease trajectory and a lower chance of survival.

\section{Interruptions to patient access to services}

Transport interruptions and travel restrictions have made accessing cervical cancer treatment more difficult for patients during the epidemic. Affordable transport options, such as motorcycle taxis (Gojek and Grab), have not been as easily accessible and the cost of a taxi or hire car is out of reach for many women. Many hospitals in regional Indonesia do not offer radiotherapy, necessitating patient travel to referral hospitals. This travel in and of itself is a barrier to accessing treatment, and is now exacerbated by the need for patients to be tested for COVID-19 before travelling.

Additionally, because cancer patients' immunity is compromised, they may wish to avoid hospitals and clinics due to the heightened risk of COVID-19 transmission. Several referral hospitals in Jakarta have observed declining numbers of cervical cancer patients presenting for chemotherapy and radiotherapy.

\section{Compromised program sustainability}

At the time of writing, the ICF's Jakarta branch experienced a dramatic blow to its program, with more than two-thirds of the annual funding allocated by the provincial government for 2020 stripped. As a consequence, the ICF's staff of 30 health workers was halved, the quota of free pap smears available to women over the next 12 months has been reduced from 4,000 to just 1,000. Additionally, home care services for patients receiving palliative care have been put on hold until further notice. Beyond 2020 the future and viability of the country's largest and oldest community-based cancer organisation in Indonesia's capital remains unclear.

\section{Role of technology}

Technology has allowed hospital-based doctors to do more of their work from home. The ICF's Jakarta Branch has also shifted its palliative care service to telemedicine. This reliance on technology in delivering health services is 
especially salient in Indonesia, which is believed to have suffered the highest rate of health worker deaths due to COVID-19 in the world.

As has been the case globally, health education activities have moved online. In recent months, we have observed a range of Zoom seminars and Facebook live talks focused on cervical cancer prevention and early detection advertised on cancer prevention network social media accounts, which are open to the public. These events previously would have been held in person and have been attracting 200 or more participants per virtual event. Those with a smartphone, tablet or computer, and a reliable internet connection, can engage in events that previously might have been impossible due to location or logistics. However poor women, who are most vulnerable to HPV and cervical cancer, are unlikely to have phones that support this technology, nor access to WiFi, and are effectively locked out of these events.

\section{Summary of impact}

Despite efforts to keep cervical cancer treatment services functioning in Jakarta the overall number of patients seeking treatment has declined, both due to the difficulties in physically accessing treatment and travel restrictions, as well as concerns associated with COVID-19 transmission. While the progress and duration of the COVID-19 pandemic cannot be predicted, we do know for certain that there is an immediate need to encourage and support patients with progressive cancers not to stay at home and not to avoid necessary treatment.

The future of cervical cancer prevention via early detection screening programs in Indonesia remains unclear. If screening does not remain a priority, fewer women will be diagnosed at earlier stages of the disease, and survival rates will decline. Over the past months, we have seen numerous decisions by the Government of Indonesia to reallocate health funds to support the immediate COVID-19 response, and this has subsequently reduced the operational funds available for cancer prevention. Additionally, the national pilot program for school-based HPV vaccination, that was active across five provinces has now stalled due to lack of funding. Within the pilot program, an estimated 120,000 girls missed their second dose in late 2019, and thus will not be protected against HPV infection [4-5]. If HPV vaccination is not quickly made a funding priority, the impact of ending the vaccination program will be felt for generations to come.

The recent budgetary strategy of moving funds from one part of the health sector to another, rather than increasing the overall funds devoted to managing the longer-term health footprint of COVID-19, is likely to be catastrophic for Indonesian women affected by gynecological cancers. Thus, we urge decision makers to focus on the long-term and broader health impacts of COVID-19 in order to reduce the overall health footprint of the pandemic on Indonesia's citizens.

\section{References}

1. Babaian J. The Pandemic's 4th Wave. hcldr. URL https:// hcldr.wordpress.com/2020/04/07/the-pandemics-4th-wave/ (accessed 8.21.20). 2020.

2. GLOBOCAN. Indonesia - Global Cancer Observatory (Fact Sheet), Population Fact Sheets. International Agency for Research on Cancer, World Health Organization, Lyon.. 2019.

3. Kemenkes, (Ministry of Health). Profil Kesehatan Indonesia 2018. Kementrian Kesehatan RI, Jakarta. 2019.

4. Kusuma A, Rachmawati D. Program Percontohan Vaksinasi HPV Anak Sekolah Kian di Ujung Tanduk. suara.com. 2019.

5. Ramdan D. Komitmen pemerintah dalam vaksinasi HPV disoal. Kontan.co.id. 2020.

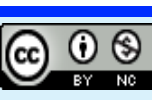

This work is licensed under a Creative Commons AttributionNon Commercial 4.0 International License. 